\title{
A Numerical Study of Strip Footing with Granular Pile Anchor Build on Expansive Soils, Wad Medani City - Sudan
}

\author{
*Hassan. A. Abas \\ *Assistant Professor, Department of Civil Engineering, Prince Mugrin University, Al-Madinah Al-Munawarah, Saudi Arabia
}

\begin{abstract}
Expansive soils in Sudan contributed to the failure of lightweight structures, resulting in increased annual maintenance costs. The purpose of this paper is to examine the effectiveness of the granular pile anchor (GPA) used with strip footing to increase resistance against swelling pressure caused by expansive soils in Wad Medan City, Sudan. The numerical study of various parameters of strip footing with GPA was achieved to come out with an effective and efficient solution for uplift damages due to expansive soils. Results indicate that the use of GPA with a strip foundation enhances the resistance capacity against swelling pressure.
\end{abstract}

Keywords: Expansive soils, strip footing, GPA, Swelling, Plaxis 3D.

\section{INTRODUCTION}

Expansive soils are widespread throughout the world, particularly in the arid and semi-arid environments. These soils swell whenever water is absorbed and shrink due to evaporation [1], [2]. Expansive soils are a challenging task in construction, especially for lightweight structures, because they tend to swell and shrink during wet-dry cycles [1], [2]. Volume changes occur due to swelling / shrinking, resulting in severe damage to the lightweight structures.

Expansive soils are frequently detected across Sudan and cause a wide variety of foundation problems. Expansive soil areas cover almost all agricultural schemes and most infrastructure projects and occupy about $40 \%$ of the total area of Sudan [3]. Extended of expansive soil challenges are generally very apparent in central and eastern Sudan. Most heavily populated areas and infrastructure investments in Sudan have concentrated in this area. The swelling pressure causes significant discomfort and damage to lightweight structures due to the inadequate foundation system [3]-[5]. This soil behavior raises the annual maintenance, and in some cases, the costs of repairing or reconstructing damaged structures exceeded the initial cost of the construction [3].
Various techniques have been recommended to avoid construction problems associated with expansive soils. The suitability of a mitigation technique depends on many parameters. However, most of them have many limitations and is very costly [6]. Recently, some study has introduced the GPA foundation system as a simple foundation technique to avoid expansive soil challenges. This approach is now being examined to evaluate it in various expansive soils condition and different types of foundations.

This study aims to examine the efficiency of using GPA to enhance the heave capacity of traditional strip footing technique used in Wad Medani City to carry lightweight structure. A numerical study using PLAXIS 3D software program was conducted to investigate the performance of strip footing constructed on expansive soil. The studied parameters include the depth of active zone, GPA depth, and space between GPA, compared with the strip footing without GPA. The change in volume of expansive soil is modeled by assigning a positive volumetric strain to the active zone cluster.

\section{EXPANSIVE SOIL IN WAD MEDANI CITY}

Wad Medani is the capital of the State of Gezira in eastcentral Sudan; it lies on the western and eastern side of the Blue Nile. It is also the headquarters and commercial city of the Gezira Scheme, one of the largest irrigation projects in the world. The clay of high plasticity and highly expansive cover a wide area of Gezira, including Wad Medani City. Saeed (2004) carried out a field survey of soil samples were collected from depths up to $6 \mathrm{~m}$ at 13 locations in the Gezira Scheme area, including Wad Medani City. The results showed that the soils of the whole area under investigation, particularly those taken from the upper $3 \mathrm{~m}$, are clay with high plasticity and a very expansive soil [7]. Hamadto (1985) conducted a field assessment of the damage caused by expansive soils at the University of Gezira complex in Wad Medani City. The reinforced strip foundation used at the University of Gezira was $0.5 \mathrm{~m}$ wide and $0.8 \mathrm{~m}$ deep. The surveyed sites are dominated with expansive soils having high 
to a very high potential for swelling. The buildings surveyed showed mild to extreme cracking.

Strip footing is extensively used in Sudan for constructing load-bearing structures, even in the case of existing expansive soil, and is widely practiced by homeowners and local contractors. Figure 1 shows the typical construction technique used to construct load-bearing walls in the State of Gezira. Unfortunately, Strip footing is suitable when the expansive soil produces slight swelling pressure. Severe cracking and damage to lightweight structures have been reported in these areas , particularly in agricultural areas, due to heave caused by expansive soils [3], [4], [7]. Figure 2 shows the typical crack and damage frequently occurred in the load bearing structure in Wad Madani city. The owners usually invested a lot of money to repair these houses.
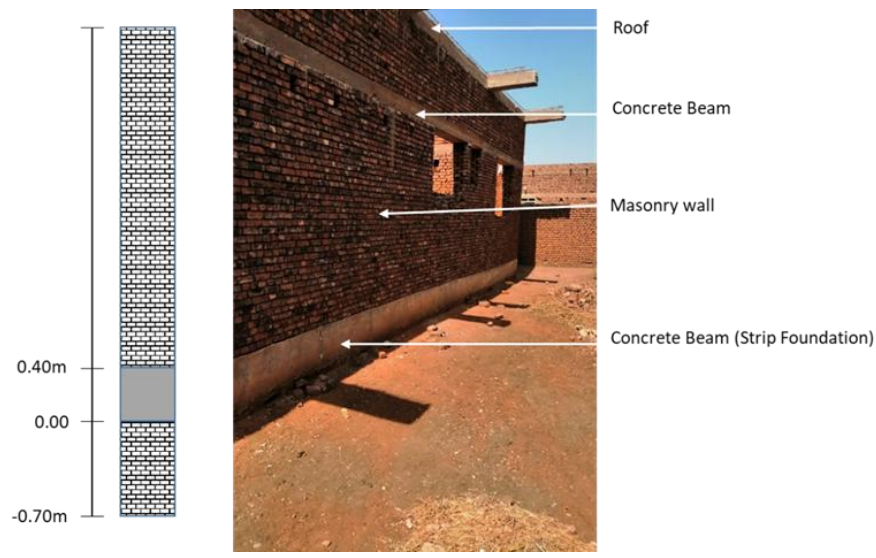

Figure 1: A typical construction technique used in Wad Madani Region, Sudan to build load-bearing walls

\section{ENHANCING STRIP FOOTING USING GPA}

In current research, a single-story load bearing construction based on the GPA strip footing is taken into account to examine the effectiveness of the GPA system for improving traditional strip footing techniques used in Sudan. Figure 3 shows the typical scheme of the concept will be examined in this paper to enhance the resistance against upheaval deformation of traditional strip footing usually used in Sudan. The concrete strip footing is anchored at the bottom of the granular pile to an anchored steel plate using a steel rod, space between granular piles is considered $2 \mathrm{~m}$. The tensionresistant in steel rod enables GPA system to avoid uplifting deformation caused by swelling of expansive soils [8], [9]. In the present study, the load bearing construction is $3 \mathrm{~m}$ high and $4 \mathrm{~m} \times 4 \mathrm{~m}$ in plan as shown in Figure 3. A slab with a thickness of $130 \mathrm{~mm}$ is considered for roofing. The idealized soil profile contains an expansive soil layer with an average thickness of $6 \mathrm{~m}$, overly dense clay with an average thickness of $9 \mathrm{~m}$.
https://doi.org/10.47001/IRJIET/2020.410001
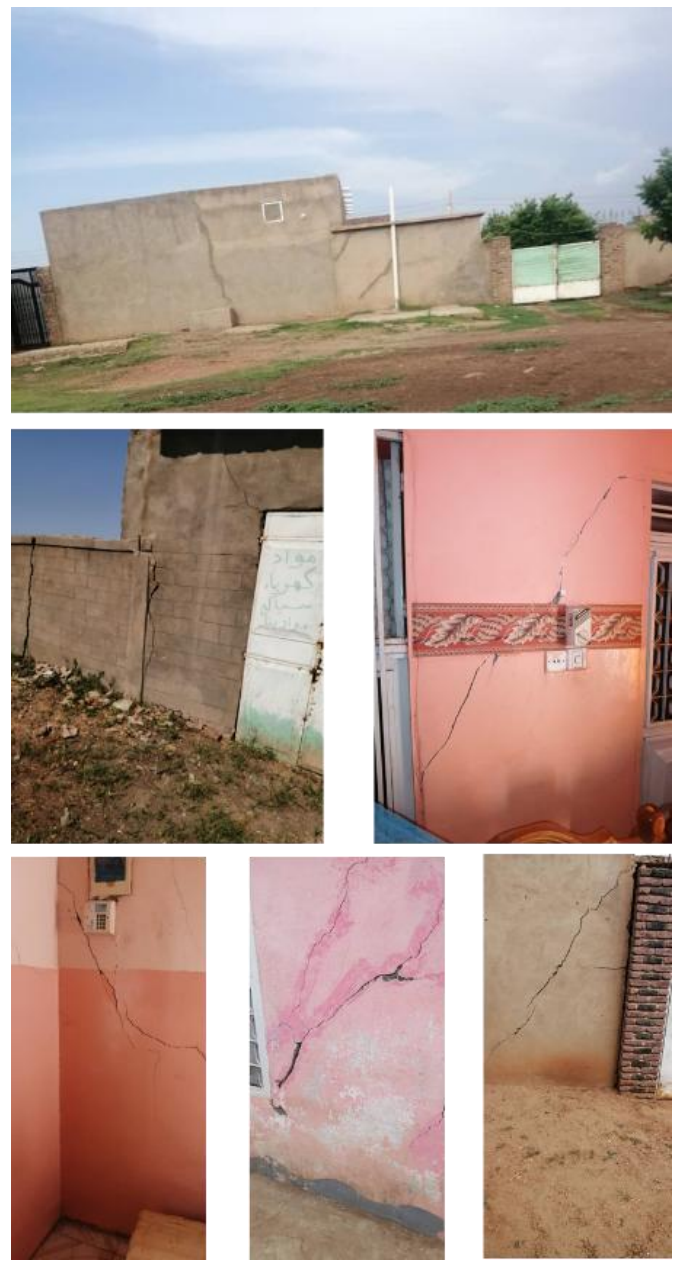

Figure 2: Example of typical bulging damage due to expansive soil, Wad Madani Region, Sudan

\section{NUMERICAL MODELLING}

The Finite element analysis was performed utilizing PLAXIS 3D software. The Model addresses heave under the strip footing connected with GPA to be constructed above expansive soil layer; for comparison, the strip footing rest on the expansive soil without GPA is also modelled. The geometry of strip footing adopted for the numerical investigation is $0.4 \mathrm{~m}$ width; these are the sizes usually used to build strip footing in Wad Madani City. The GPA length was varied from $(2 \mathrm{~m}$ and 2.5$) \mathrm{m}$, and the diameter of anchored steel plate is $0.25 \mathrm{~m}$. The thickness of expansive clay layer is fixed at $6 \mathrm{~m}$. The active zone of the expansive soil is the wetted depth, which was chosen to be $0.5 \mathrm{~m}, 1 \mathrm{~m}, 1.5 \mathrm{~m}$, and 2 $\mathrm{m}$.

The finite element mesh of the footing is shown in Figure 4. The mesh size is refined to achieve the best and most accurate results. The boundary condition was taken as standard fixity in which roller supports are assumed for vertical boundary surface and entirely fixed state at the base of the soil bed. 


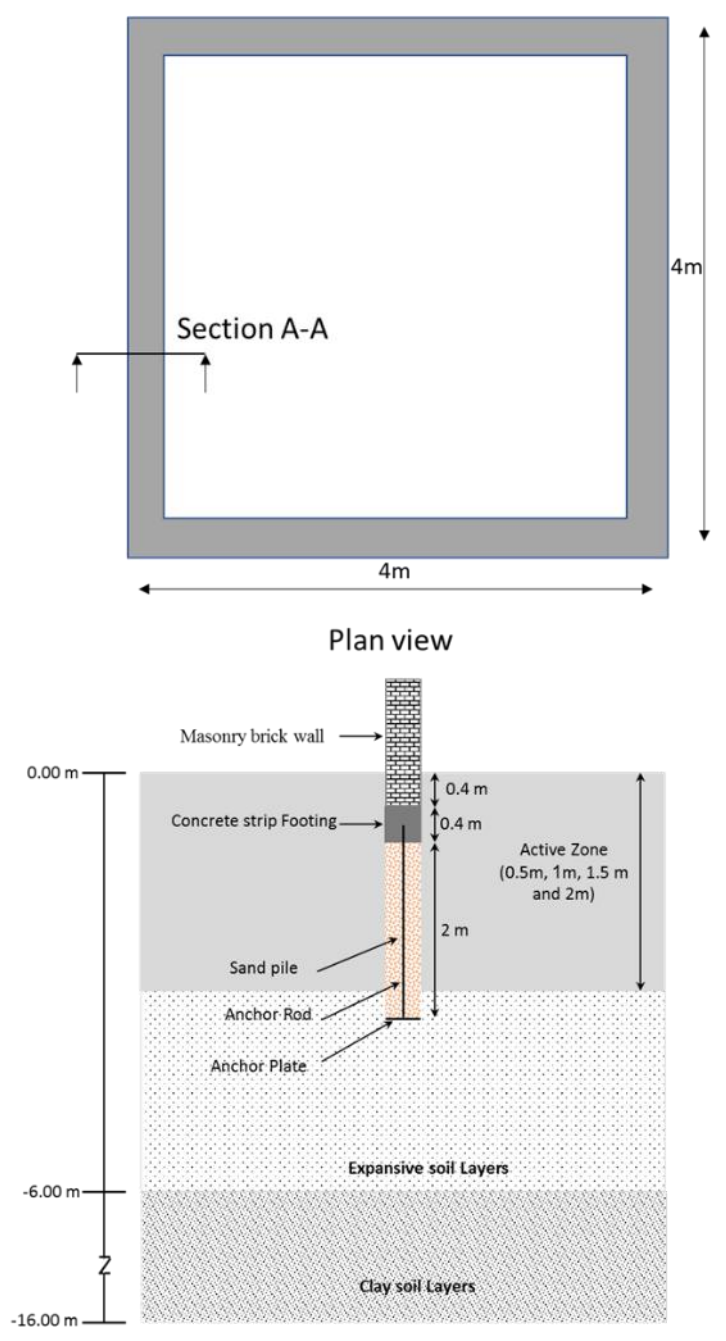

Section A-A

Figure 3: A typical scheme of strip footing with GPA system proposed to enhance strip footing in Wad Madani City, Sudan

The swelling deformation action in the wetted active zone is simulated by applying a positive volumetric strain $(7.5 \%)$ to the active zone. In fact, the rate at which expansive soil will naturally swell varies from place to place, depending on the source of moisture and the magnitude of the applied load.

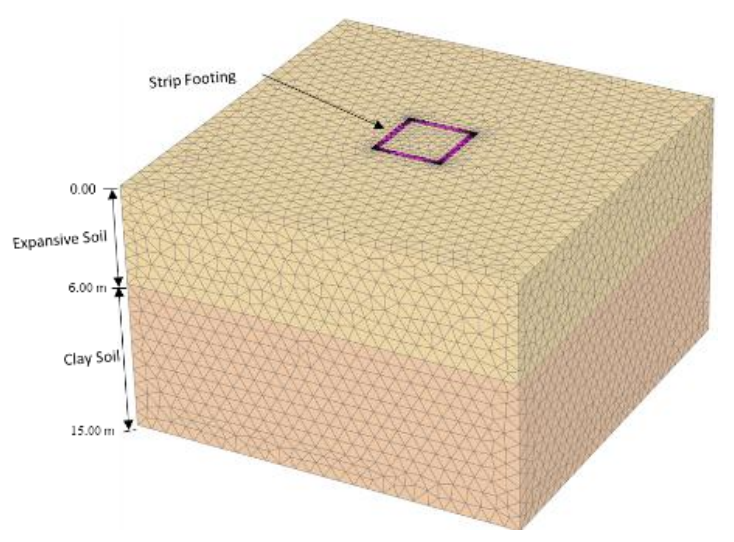

ISSN (online): 2581-3048

Volume 4, Issue 10, pp 1-6, October-2020 https://doi.org/10.47001/IRJIET/2020.410001

Soil layers profiles were modelled using borehole feature available in PLAXIS 3D. The expansive clay soil considered around the GPA was modelled using Mohr-Coulomb material model with undrained conditions. The soil layers properties were obtained from previous studies done in Wad Medani City [3], [7], [10]. The GPA properties have been derived from several previous researches. [9], [11]. The model used for the granular pile was modelled using Mohr-Coulomb with a drained condition. The properties assigned to expansive soil and granular aggregates are enlisted in Table 1.

The anchoring plate is modelled using a linear elastic plate element, while the steel rod is modelled using a linear elastic node-to-node model. The Normal stiffens of steel rod is $5 \times 10^{5} \mathrm{kN}$.The strip footing concrete was modelled as a rigid plate, and the load was applied to the surface following the loading scheme applied during the actual field loading. The parameters of GPA and strip footing are presented in Table 2. The rigid concrete foundation and the surface layer of the soil have no interface element because there is no slippage between the plate and the soil under the plate [12].

Table 1: The value adopted for the FEM of soil layers and granular aggregates

\begin{tabular}{|l|c|c|c|}
\hline \multicolumn{1}{|c|}{ Parameter } & $\begin{array}{c}\text { Expansive } \\
\text { Soil }\end{array}$ & $\begin{array}{c}\text { Natural } \\
\text { clayey soil }\end{array}$ & $\begin{array}{c}\text { Granular } \\
\text { soil }\end{array}$ \\
\hline $\begin{array}{l}\text { Unsaturated unit } \\
\text { weight }\left(k N / m^{3}\right)\end{array}$ & 17 & 18 & 18 \\
\hline $\begin{array}{l}\text { Saturated unit } \\
\text { weight }\left(k N / m^{3}\right)\end{array}$ & 19 & 19 & 20 \\
\hline $\begin{array}{l}\text { Cohesion, } \\
\left(k N / m^{2}\right)\end{array}$ & 90 & 120 & - \\
\hline Friction angle, $\left(^{\circ}\right)$ & 18 & 27 & 37 \\
\hline $\begin{array}{l}\text { Elastic modulus E } \\
(\text { MPa })\end{array}$ & 5,10 & 35 & 50 \\
\hline Passion ratio & 0.4 & 0.4 & 0.3 \\
\hline
\end{tabular}

Table 2: Material properties of concrete footing, anchor plate, and anchor rod

\begin{tabular}{|c|c|c|}
\hline Parameter & Concrete Footing & Anchor plate \\
\hline $\begin{array}{c}\text { Elastic modulus E } \\
(\mathrm{MPa})\end{array}$ & $31 \times 10^{3}$ & $200 \times 10^{3}$ \\
\hline Unit Weight (kN/m3) & 24 & 76 \\
\hline Poisson's ratio & 0.2 & 0.1 \\
\hline Thickness, (m) & 0.4 & 0.002 \\
\hline
\end{tabular}

Figure 4: the geometry model of footing 
ISSN (online): 2581-3048

\section{RESULTS AND DISCUSSIONS}

Series of Plaxis 3D models were conducted to investigate the efficiency of GPA in mitigating the swelling effect. The numerical results of strip concrete footing both with and without GPA on expansive clay were obtained and discussed in this section.

\section{a) Effect of GPA on Heave Displacement}

The results showed that in the case of using GPA, the maximum heave of the strip footing decreased. Efficiency of the GPA in arresting the heave displacement of strip footing is illustrated in Figure 5, which shows the comparison between heave displacement of strip footing with and without GPA. This improvement is primarily due to the tension forces in the GPA steel rod as shown in

Figure 6. The stress forces in the steel rod increase by increasing the depth of the active zone.

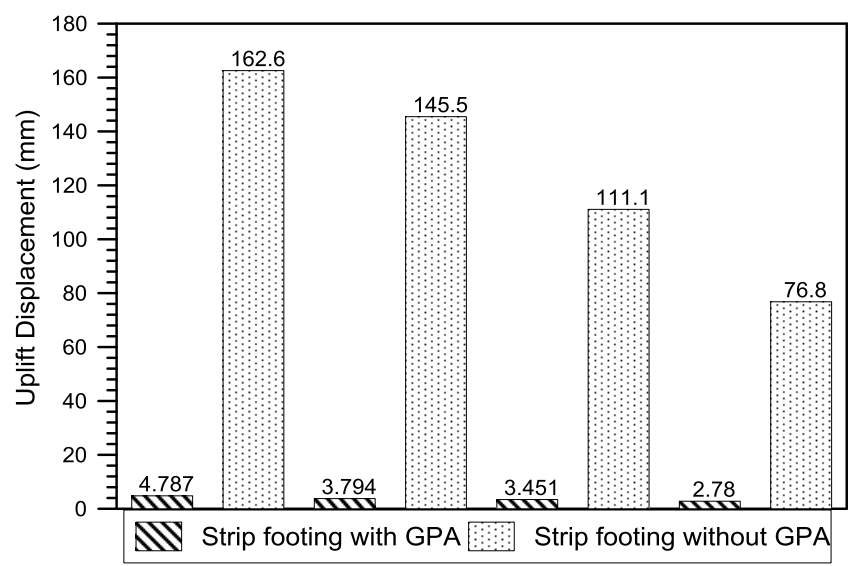

Figure 5: Comparison between the heave displacement of the strip with and without GPA

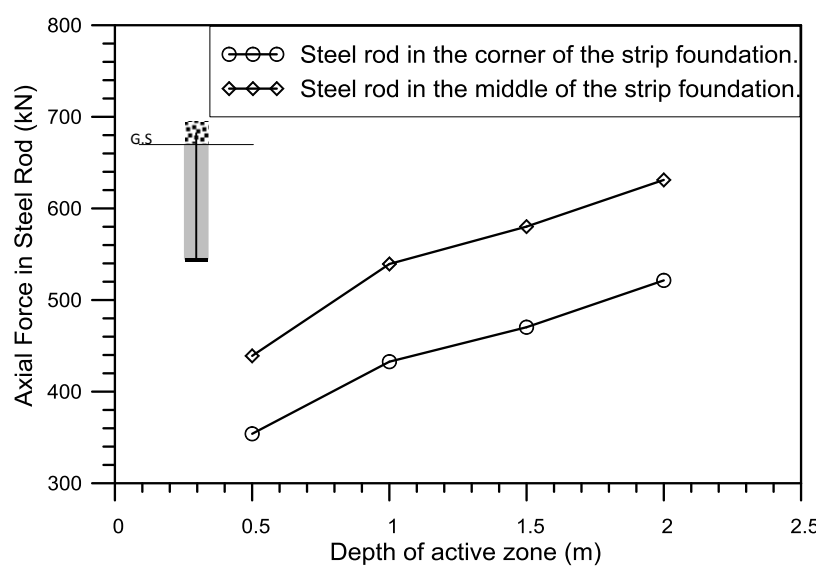

Figure 6: Relationship between the tension forces in the steel rod and the depth of the active zone
https://doi.org/10.47001/IRJIET/2020.410001

Table 3shows the percentage reduction in heave, PRH in the case of strip footing with or without GPA. The PRH is calculated from the following equation [13].

Percentage reduction in heave, $\mathrm{PRH} \%=\left(\frac{h-h^{\prime}}{h}\right) \times 100$

Where:

(h): is the maximum heave of footing without (GPA).

$\left(h^{\prime}\right)$ : is the maximum heave of footing with (GPA).

Table 3 demonstrates that, if the GPA system is used, it greatly increases the capacity of the strip footing to withstand the vertical movement caused by expansive soil.

Table 3: percentage reduction in heave of strip footing with GPA

\begin{tabular}{|c|c|c|c|}
\hline $\begin{array}{c}\text { Active } \\
\text { Zone } \\
\text { Depth } \\
\text { (m) }\end{array}$ & $\begin{array}{c}\text { Length } \\
\text { of GPA } \\
\text { (m) }\end{array}$ & $\begin{array}{c}\text { Space } \\
\text { between } \\
\text { GPA } \\
\text { (m) }\end{array}$ & $\begin{array}{c}\text { Percentage } \\
\text { reduction in } \\
\text { heave, PRH } \\
\text { \% }\end{array}$ \\
\hline 0.5 & 2 & 2 & 96.38 \\
\hline 1 & 2 & 2 & 96.89 \\
\hline 1.5 & 2 & 2 & 97.39 \\
\hline
\end{tabular}

\section{b) Effect of Thickness of the Active Zone}

The findings showed that the maximum heave of strip footing increase as the depth of the active zone increases. The heave increases gradually with the length away from GPA and decreases to the minimum values at the head of GPA as shown in Figure 7.

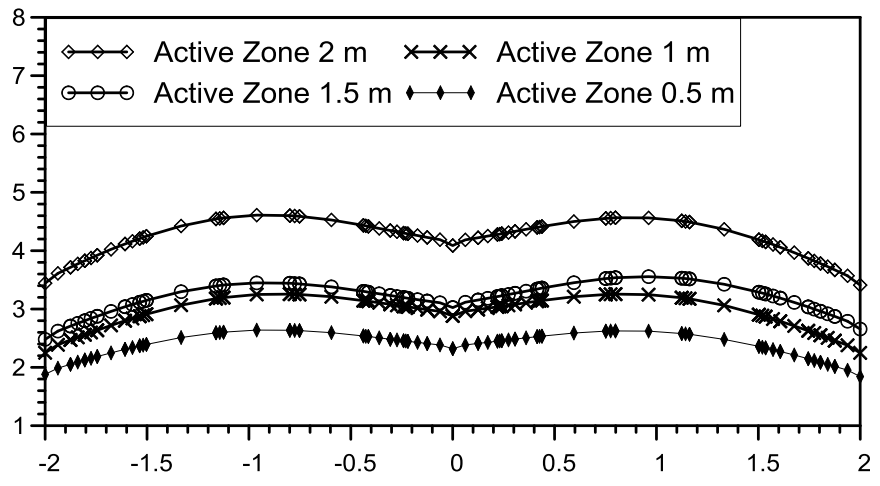

Figure 7: Heave displacement at the top of strip footing with GPA

\section{c) Effect of GPA Spacing}

The results showed that the maximum heave of the strip footing decreased with the decreasing of the GPA spacing. Using GPA with a spacing of $2 \mathrm{~m}$ and a length of $2.0 \mathrm{~m}$, minimize the upward movement of strip footing from 145.5 $\mathrm{mm}$ to $3.794 \mathrm{~mm}$. On other hand, using GPA with a spacing of $1 \mathrm{~m}$ at the same depth the displacement of the strip footing is 
ISSN (online): 2581-3048

reduced to $1.806 \mathrm{~mm}$. The vertical displacement induced by soil heave on the top of strip footing with a GPA spacing of 1 $\mathrm{m}$ and $2 \mathrm{~m}$ is shown in Figure 8.

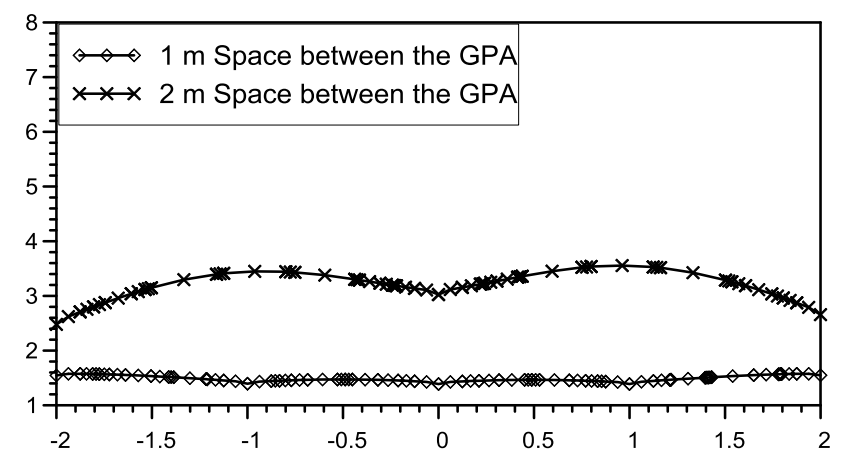

Figure 8: Deformation of strip footing with GPA due to heave

\section{CONCLUSIONS}

The paper focuses on the study of the efficacy and capacity of the GPA approach to mitigate the heave of the conventional strip footing technique used in Wad Medani Area, Sudan. The conclusions drawn from this paper can be summarized as follows:

1. Expansive soils in Wad Madani Region, Sudan have contributed to the failure of light structures and, as a result, increased annual maintenance costs.

2. The use of the GPA method for lightweight structures will significantly reduce the risk caused by expansive soils, resulting in significant savings in structural repair costs and continuing maintenance.

3. The study showed that the GPA had to be extended to a stable zone to improve the ability of the GPA to withstand elevation.

4. The maximum height of the GPA-strip footing system is governed by the depth of the GPA in the stable zone and the structure specifications of the GPA. The heave is also reduced by decreasing GPA space.

5. The use of GPA strips footing has a significant effect in the situation of an active expansive soil zone at shallow depths not exceeding $2 \mathrm{~m}$.

\section{REFERENCES}

[1] J. Nelson and D. J. Miller, Expansive soils: problems and practice in foundation and pavement engineering. John Wiley \& Sons, 1997.

[2] F. H. Chen, Foundations on expansive soils, vol. 12. Elsevier, 2012.

[3] W. A. Charlie, M. A. Osman, and E. M. Ali, 'Construction on expansive soils in Sudan', $J$. Constr. Eng. Manag., vol. 110, no. 3, pp. 359-374, 1984.
[4] E. M. Lates, B. E. F. Elmonshid, and S. H. Abbo, 'Review of Problems Generated by Expansive Soils in Sudan', 1983.

[5] H. A. M. ABAS, 'The Study of Behaviour of PileCap in Expansive SoilsUsing a Finite Element Softening Model', PhD Thesis, Sudan University of Science \&Technology, 2007.

[6] M. A. Dafalla, M. A. Al-Shamrani, A. J. Puppala, and H. E. Ali, 'Design guide for rigid foundation systems on expansive soils', Int. J. Geomech., vol. 12, no. 5, pp. 528-536, 2012.

[7] I. M. A. Saeed, 'Evaluation of improvement techniques for strip foundation on expansive clay soils in Gezira', PhD Thesis, PhD Thesis. Khartoum, Sudan: University of Khartoum, 2004.

[8] B. R. Phanikumar, A. Srirama Rao, and K. Suresh, 'Field behaviour of granular pile-anchors in expansive soils', Proc. Inst. Civ. Eng.-Ground Improv., vol. 161, no. 4, pp. 199-206, 2008.

[9] B. R. Phanikumar, R. S. Sharma, A. S. Rao, and M. R. Madhav, 'Granular pile anchor foundation (GPAF) system for improving the engineering behavior of expansive clay beds', Geotech. Test. J., vol. 27, no. 3, pp. 279-287, 2004.

[10] A. M. El-sharief, 'Foundations on Expansive Soils Sudan Experience', 2009.

[11] H. A. Abbas, 'Numerical model of stone column in sabkha soil', Int. Res. J. Innov. Eng. Technol. IRJIET, vol. 3, no. 9, pp. 8-11, 2019.

[12] H. A. Abas, 'Performance and Design Optimization of Stone Column in Sabkha Soils', PhD Thesis, King Fahd University of Petroleum and Minerals (Saudi Arabia), 2015.

[13] S. Sangeetha and P. H. Krishna, 'Analysis of Heave Behaviour of Expansive Soil Provided with Granular Pile Anchors Using Plaxis', in Advances in Computer Methods and Geomechanics, Springer, 2020, pp. 391-404.

\section{AUTHOR'S BIOGRAPHY}

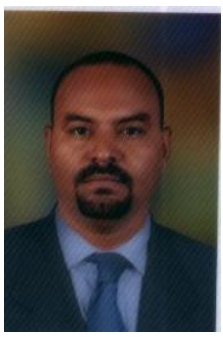

Name : Hassan Ali Mohamad Abas

Nationality : Sudanese

Date of Birth :1/1/1977

Email : $\underline{\text { H.Abbas@upm.edu.sa }}$

hassankfupm@gmail.com

Educational Qualification: $\mathrm{PhD}$

(Geotechnical Engineering) King Fahd University of Petroleum and Minerals, Dhahran, Saudi Arabia, 2015. 


\section{Citation of this Article:}

Hassan. A. Abas, "A Numerical Study of Strip Footing with Granular Pile Anchor Build on Expansive Soils, Wad Medani City - Sudan" Published in International Research Journal of Innovations in Engineering and Technology - IRJIET, Volume 4, Issue 10, pp 1-6, October 2020. https://doi.org/10.47001/IRJIET/2020.410001 